\title{
Uterotonics for prevention of postpartum haemorrhage: EN-BIRTH multi-country validation study
}

Harriet Ruysen ${ }^{1 * \dagger}$, Josephine Shabani ${ }^{2 \dagger}$, Claudia Hanson ${ }^{3}$, Louise T. Day ${ }^{1}$, Andrea B. Pembe ${ }^{4}$, Kimberly Peven ${ }^{1,5}$, Qazi Sadeq-ur Rahman ${ }^{6}$, Nishant Thakur ${ }^{7}$, Kizito Shirima ${ }^{2}$, Tazeen Tahsina ${ }^{6}$, Rejina Gurung ${ }^{7}$, Menna Narcis Tarimo ${ }^{2}$, Allisyn C. Moran ${ }^{8 \dagger}$, Joy E. Lawn ${ }^{1 \dagger}$ and EN-BIRTH Study Group

\begin{abstract}
Background: Postpartum haemorrhage (PPH) is a leading cause of preventable maternal mortality worldwide. The World Health Organization (WHO) recommends uterotonic administration for every woman after birth to prevent $\mathrm{PPH}$. There are no standardised data collected in large-scale measurement platforms. The Every Newborn Birth Indicators Research Tracking in Hospitals (EN-BIRTH) is an observational study to assess the validity of measurement of maternal and newborn indicators, and this paper reports findings regarding measurement of coverage and quality for uterotonics.

Methods: The EN-BIRTH study took place in five hospitals in Bangladesh, Nepal and Tanzania, from July 2017 to July 2018. Clinical observers collected tablet-based, time-stamped data. We compared observation data for uterotonics to routine hospital register-records and women's report at exit-interview survey. We analysed the coverage and quality gap for timing and dose of administration. The register design was evaluated against gap analyses and qualitative interview data assessing the barriers and enablers to data recording and use.

Results: Observed uterotonic coverage was high in all five hospitals (>99\%, 95\% Cl 98.7-99.8\%). Survey-report underestimated coverage (79.5 to 91.7\%). "Don't know" replies varied (2.1 to 14.4\%) and were higher after caesarean (3.7 to 59.3\%). Overall, there was low accuracy in survey data for details of uterotonic administration (type and timing). Register-recorded coverage varied in four hospitals capturing uterotonics in a specific column (21.6, 64.5, 97.6, 99.4\%). The average coverage measurement gap was $18.1 \%$ for register-recorded and $6.0 \%$ for survey-reported coverage. Uterotonics were given to $15.9 \%$ of women within the "right time" $(1 \mathrm{~min})$ and $69.8 \%$ within 3 min. Women's report of knowing the purpose of uterotonics after birth ranged from 0.4 to $64.9 \%$ between hospitals. Enabling register design and adequate staffing were reported to improve routine recording.

(Continued on next page)
\end{abstract}

\footnotetext{
* Correspondence: Harriet.Ruysen@lshtm.ac.uk

${ }^{\dagger}$ Harriet Rusyen and Josephine Shabani are joint first authors.

${ }^{+}$Allisyn C. Moran and Joy E. Lawn are joint senior authors.

${ }^{1}$ Centre for Maternal, Adolescent, Reproductive \& Child Health (MARCH),

London School of Hygiene \& Tropical Medicine (LSHTM), London, UK

Full list of author information is available at the end of the article
}

\section{$\triangle B M C$}

c) The Author(s). 2021 Open Access This article is licensed under a Creative Commons Attribution 4.0 International License which permits use, sharing, adaptation, distribution and reproduction in any medium or format, as long as you give appropriate credit to the original author(s) and the source, provide a link to the Creative Commons licence, and indicate if changes were made. The images or other third party material in this article are included in the article's Creative Commons licence, unless indicated otherwise in a credit line to the material. If material is not included in the article's Creative Commons licence and your intended use is not permitted by statutory regulation or exceeds the permitted use, you will need to obtain permission directly from the copyright holder. To view a copy of this licence, visit http://creativecommons.org/licenses/by/4.0/. The Creative Commons Public Domain Dedication waiver (http://creativecommons.org/publicdomain/zero/1.0/) applies to the data made available in this article, unless otherwise stated in a credit line to the data. 
(Continued from previous page)

Conclusions: Routine registers have potential to track uterotonic coverage - register data were highly accurate in two EN-BIRTH hospitals, compared to consistently underestimated coverage by survey-report. Although uterotonic coverage was high, there were gaps in observed quality for timing and dose. Standardisation of register design and implementation could improve data quality and data flow from registers into health management information reporting systems, and requires further assessment.

Keywords: Birth, Maternal, Coverage, Validity, Survey, Hospital records, Health management systems, Uterotonics, Postpartum haemorrhage

\section{Key findings}

\section{What is known and what is new about this study?}

- Administration of prophylactic uterotonics immediately after birth is an evidence-based intervention with the potential to reduce postpartum haemorrhage (PPH) related deaths by half, yet there are no reliable data tracking current coverage at national or global level for most low and middle-income countries (LMICs).

- EN-BIRTH is the first and largest observational study ( $n=23,015$ women) with mixed methods to assess validity of uterotonic measurement around the time of birth in three LMICs. Custom-built tablet-based software generated time-stamped observation data. Qualitative research explored barriers and enablers to inform improvements for routine register recording of uterotonic use.

Survey-what did we find and what does it mean?

- Our findings show women's reports about care received around the time of birth underestimate uterotonics coverage; this aligns with results from previous studies.

- There was low accuracy in survey data for details of uterotonic administration (type of drug and timing of administration). We do not recommend the addition of a uterotonic indicator to household survey platforms.

- "Don't know" responses were highest for women having a caesarean birth.

Register-what did we find and what does it mean?

- Register design was critical: one did not capture uterotonics at all.

-When uterotonics were recorded in specific columns, coverage was accurately measured in two hospitals but underestimated in two hospitals, suggesting that good register design is necessary, but not sufficient to achieve high quality data.

Gap analysis for quality of care and measurement

- Uterotonic coverage was high (>99\%) in these five hospitals.

- Actionable gaps were identified for timing - only 15.9\% of women received uterotonics within the recommended $1 \mathrm{~min}$, and $69.8 \%$ of women within $3 \mathrm{~min}$.

- The correct dose of oxytocin was received by $63.3 \%$ of women.

What next and research gaps?

- Uterotonic coverage was high, so we need to move beyond coverage, and measure the quality of uterotonic administration. Data sources such as local audits - as well as service readiness or health facility assessments monitoring drug quality, stock

management and provider practices - are needed.

- Further research to explore data flow and quality at different levels of the HMIS, and measures of effective coverage, is also warranted.

- Registers have potential to accurately capture provision of

uterotonics and could provide regular data with standardised design and implementation.

\section{Background}

An estimated 295000 maternal deaths occur annually worldwide, $99 \%$ are in low and middle income countries (LMICs) [1]. Approximately one-quarter of maternal deaths are caused by haemorrhage, with postpartum haemorrhage $(\mathrm{PPH})$ estimated to affect around 7 million women each year [2, 3]. Administration of prophylactic uterotonics immediately after birth is an evidence-based intervention with potential to halve PPH-related deaths [4]. The World Health Organization (WHO) recommends provision of prophylactic uterotonics for every woman during the third stage of labour [5]. Five drugs are available for $\mathrm{PPH}$ prevention: oxytocin, carbetocin, ergometrine, misoprostol, and prostaglandin. An intramuscular (IM) injection of oxytocin plus ergometrine is most effective, although oxytocin alone is currently the most widely used uterotonic for facility births [4]. Despite uterotonics being prioritised by WHO as an essential intervention, there are currently no national or global level data to track coverage. Several estimates based on expert opinion suggest low coverage [6, 7], and one study found coverage under $50 \%$ in three settings with low facility-birth rates [8].

Data on coverage, equity and quality of care are fundamental to achieving Universal Health Coverage and driving progress towards meeting the Sustainable Development Goals for maternal and neonatal mortality, as well as addressing morbidities, by $2030[9,10]$. Quality of care at birth is prioritised by both Every Newborn and Ending Preventable Maternal Mortality (EPMM) strategies [11-13]. The Every Newborn Action Plan, passed by all United Nations member states and agreed by more than 80 development partners, includes an ambitious measurement improvement roadmap with an urgent focus on validating indicators for selected maternal and newborn care interventions [13, 14].

Coverage is defined as the proportion of individuals receiving an intervention (numerator: 'number of women receiving prophylactic uterotonics immediately after birth in a health facility) from among the population in need of that intervention (denominator: all women giving birth in the facility') [15, 16]. The use of live births as the denominator is common for many maternal health indicators such as place of birth, skilled attendance or caesarean section [6], but should be carefully evaluated for appropriateness against each indicator.

Population-based surveys such as the Demographic and Health Survey (DHS) and Multiple Indicator Cluster Survey (MICS) remain the major data sources for 
pregnancy outcomes and coverage of care data for the $75 \%$ of births occurring in LMICs [17-19]. Currently, there is no uterotonic indicator measured in core survey modules for DHS or MICS. Previous research to assess validity of surveys suggest women do not accurately report uterotonic administration [20-23]. In two of five studies, agreed cut-offs for population-level validity were met, but none met individual-level validity thresholds [20, 21] (Additional file 1). This is compatible with further evidence suggesting that asking women about clinical interventions provided during or immediately after birth is not reliable [20-24].

Facility-based births in LMICs have increased dramatically in the last decade, now reaching four out of every five births [25]. Data recorded in facility registers and aggregated as part of health management information systems (HMIS) offer an alternative measurement platform, which could provide more frequent information if concerns about data quality and completeness are addressed [26]. Only one previous observational study $(n=1867)$ in Nigeria has assessed register-recorded accuracy compared with observerassessed coverage for uterotonics [27]. They found accurate measurement with nearly complete agreement between register-recorded and observer-assessed data for uterotonics, but were unable to analyse individual-level validity due to high intervention prevalence [27]. In a descriptive assessment of birth registers in 37 countries, only 16 were tracking uterotonics use in any routine record, including maternity registers, birth records, or electronic data platforms [7].

The Every Newborn - Birth Indicators Research Tracking in Hospitals (EN-BIRTH) study was an observational study of $>23,000$ hospital births in three countries (Tanzania, Bangladesh and Nepal). The detailed protocol as well as overall validity results, are reported elsewhere $[15,28]$.

\section{Objectives}

This paper is part of a supplement based on the ENBIRTH multi-country validation study, Informing measurement of coverage and quality of maternal and newborn care', and focuses on uterotonic provision with four objectives:

1. Assess NUMERATOR accuracy/validity of uterotonic coverage measurement using exit survey of women's report, and routine labour ward registers compared to direct observation (gold standard).

2. Compare DENOMINATOR options for uterotonic coverage: including live births, or total births (live births and stillbirths).
3. Analyse GAPS in coverage and quality of care, and measurement for uterotonics: coverage and quality gaps relating to provision of care (right time, right drug, and right dose) and experience of care (survey report of reason for uterotonics given).

4. Evaluate BARRIERS AND ENABLERS to routine labour ward register recording for uterotonics through qualitative interviews regarding register design filling and use.

\section{Methods}

EN-BIRTH study compared observation of uterotonic administration for prevention of PPH (gold standard) to coverage measured by women's report at exitinterview survey, and routine register records (Fig. 1). Gold standard data were collected by trained clinical researchers covering $24 \mathrm{~h}$ per day and using a custom-built android tablet-based software application [15].

Five comprehensive emergency obstetric care (CEmOC) hospitals in three study countries were included because they were implementing the selected interventions: Maternal and Child Health Training Institute, Azimpur and Kushtia General Hospital in Bangladesh (BD), Pokhara Academy Health Sciences in Nepal (NP), and Muhimbili National Hospital and Temeke District Hospital in Tanzania (TZ). Participants were consenting women admitted to the labour and birth wards in the five study sites. Data collection was undertaken between July 2017 and July 2018. This study was granted ethical approval by institutional review boards in all operating countries in addition to the London School of Hygiene \& Tropical Medicine (Additional file 2). Results are reported in accordance with STROBE statement checklists for cross-sectional studies (Additional file 3).

Labour ward registers varied in design between the five sites. Nepal had no uterotonics column. The original Bangladesh hospital registers, and an additional 'midwifery book' maintained in Muhimbili, had a nonspecific column option (such as 'drugs'). Bangladesh registers were updated to a standardised national register during the study (Additional file 4). Tanzanian and the updated Bangladesh registers used for this analysis had a specific column for third stage management, labelled 'AMTSL' (active management of the third stage). In Bangladesh, staff ticked the column if AMTSL (including uterotonic administration) was considered done, and left the column blank for not done. The AMTSL column in Tanzania was completed with an "O, E or M" denoting oxytocin, ergometrine or misoprostol administration. There was a further column in the Tanzania registers where staff could write "yes" if any type of uterotonic 


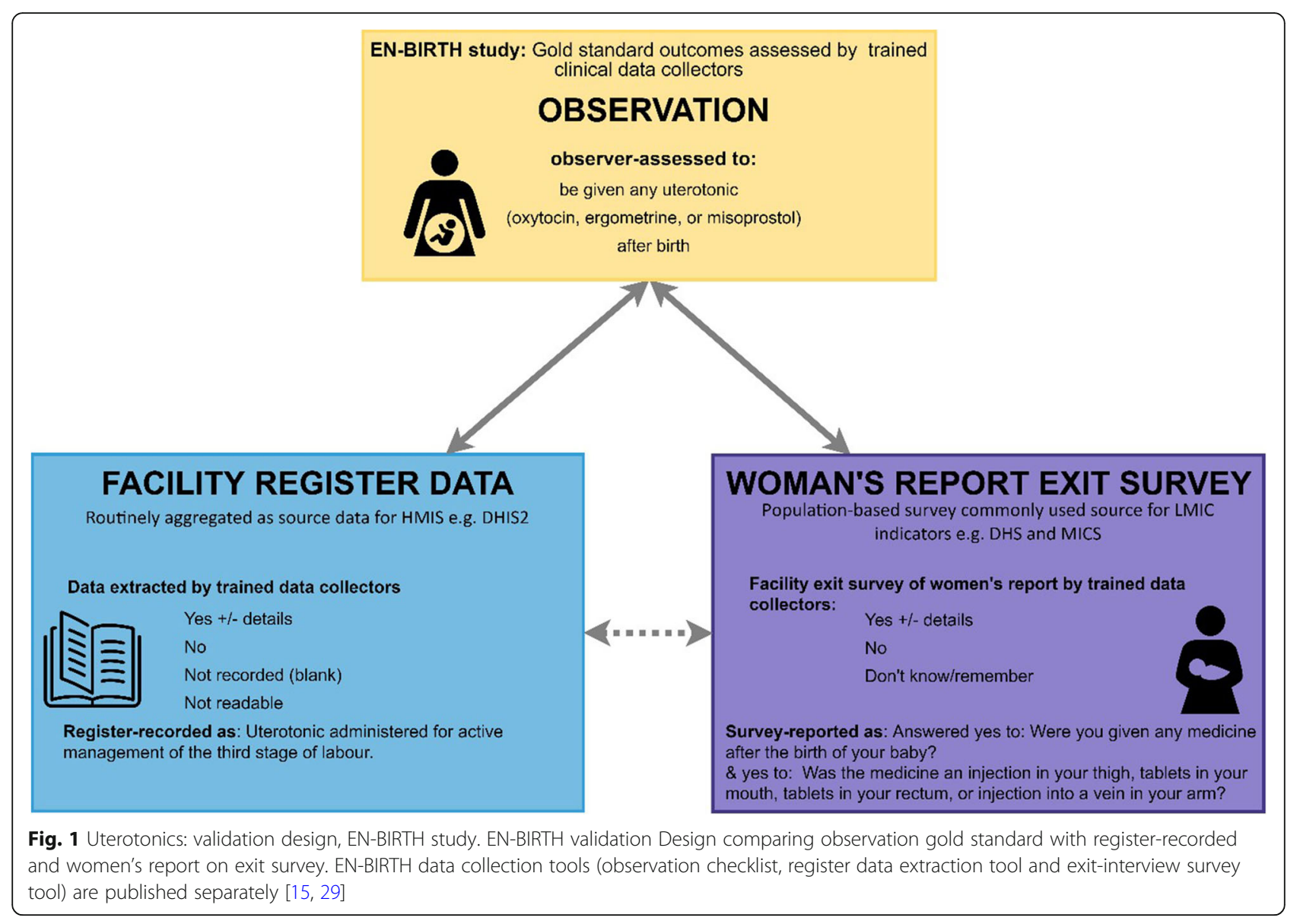

was administered, or "no" if no uterotonic was administered. Full details of register design and use are available in Additional file 5.

One year of pre-study register data were extracted and compared to one-year of during-after study register records to assess if the presence of external researchers in the hospital affected register recording practice $[28,30]$. To determine reliability of the observational data, Cohen's Kappa coefficients of agreement were calculated for a $5 \%$ subset of cases where study supervisors simultaneously observed/extracted data for comparison with data collector's findings (Additional file 6) [28].

\section{Objective 1: Numerator validation}

We assessed the performance of a range of individual and combined exit-survey questions around uterotonic administration for prevention of $\mathrm{PPH}$, compared to observer-assessed practice (Fig. 2). All results were stratified by mode of birth (vaginal births and caesareans) and presented by individual site, and overall. For indicators which had $\geq 10$ counts in both columns of the $2 \times 2$ table, we calculated percent agreement, sensitivity, and specificity, positive and negative predictive values, area under the receiver operating curve, and inflation factor. We combined hospital data using random effects meta-analysis [28]. The percentage of women answering "don't know" to survey questions was calculated and analysed in two ways: "don't know" considered as "no" and with "don't know" excluded [28]. If there were missing data elements for the numerator or denominator, the participant was excluded from the relevant sample. Nepal was excluded from register-recorded validation calculations given the absence of a uterotonic column. Exit-interview indicator combinations were explored using descriptive analysis comparing women's report for different combined indicator options with observation data (Additional file 7). Quantitative analyses were undertaken using StataCorp: Stata Statistical Software (Release 16. In. College Station, TX; 2019).

\section{Objective 2: Denominator comparison}

The denominator was all women who gave birth; however, we also calculated coverage using live birth and total birth denominator options for observerassessed uterotonic coverage data. Descriptive analysis was used to compare these results. 


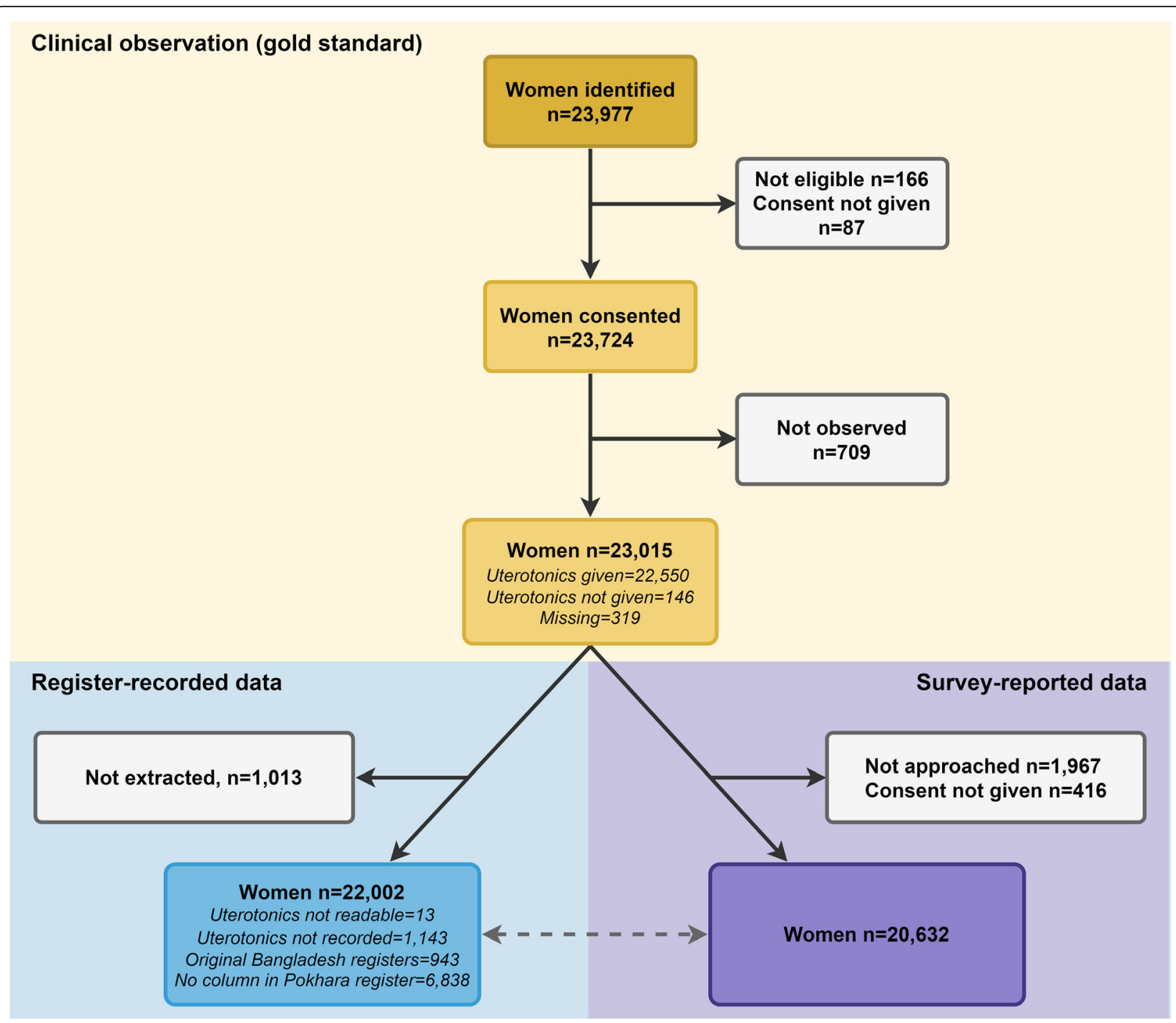

Fig. 2 Flow diagram for uterotonic cases, EN-BIRTH study $(n=23,015)$

Objective 3: Gap analysis for coverage and quality of care and measurement

We analysed four gaps for uterotonic administration: 1) Coverage gap between the all-birth target population and observed uterotonic coverage. 2) Quality of care gap between any observed uterotonic coverage, and high quality uterotonic coverage (within the right time $<1$ or $<3 \mathrm{~min}$, at the right dose 10 international units (IU) oxytocin). 3) Measurement gap for register-records. 4) Measurement gap for survey reports. Results were stratified by site and by mode of birth, univariate logistic regression was used to explore the association between timing of uterotonic administration and mode of birth.

\section{Objective 4: Barriers and enablers to data collection}

Qualitative data collection tools for focus group interviews were informed by the Performance of Routine
Information System Management (PRISM) conceptual framework [31]. A purposive sample of hospital health workers (nurses, midwives and doctors) and EN-BIRTH data collectors was used. Interview audio recordings were transcribed, translated and coded using a priori code and included constructs for Technical, Organisational and Behavioural factors. NVivo 12 software was used to manage data. Respondents also completed a checklist regarding: who usually gives the uterotonic, documents care, which documents uterotonics are recorded in, the order documentation occurs, and estimations of how long after birth uterotonics are documented. More information is available within this supplement [32].

\section{Results}

Across five study hospitals, 23,724 (99.6\%) women consented to participate, with 23,015 (97.0\%) observed 
and 20,632 (86.6\%) completing an exit survey. Register extraction was completed for 22,002 (92.7\%) women (Fig. 2). Participant characteristics are shown in Table 1. Nearly half of participants were presenting with their first pregnancy and participants from Tanzania were most likely to be multiparous (2+ previous births). The proportion of normal vaginal births varied between hospitals, from $26.4 \%$ in Azimpur, BD to $91.6 \%$ in Temeke, TZ (Table 1). The highest proportion of caesarean births were in Azimpur BD (72.8\%) and Muhimbili, TZ (55.8\%). 688 (3.2\%) women experienced PPH during the study.

\section{Objective 1: Numerator validation}

Observed uterotonic coverage was consistently high across all sites and modes of birth (range from $98.4 \%$ in Muhimbili, TZ to $99.9 \%$ in Pokhara, NP) (Fig. 3). Of those administered uterotonics, $>99 \%$ received oxytocin, irrespective of mode of birth (Additional file 8).

\section{Exit-interview survey-reported findings}

Survey-reported uterotonic coverage ranged from 79.5\% in Muhimbili to $91.7 \%$ in Temeke TZ; $84.7 \%$ (95\% CI 79.1-89.5) overall (Additional file 9). Women who had a vaginal birth were more likely to accurately report

Table 1 Characteristics of women observed in labour and delivery wards, EN-BIRTH study $(n=23,015)$

\begin{tabular}{|c|c|c|c|c|c|c|}
\hline & \multicolumn{5}{|l|}{ Hospitals } & \multirow[t]{3}{*}{ Total } \\
\hline & \multicolumn{2}{|l|}{ Bangladesh } & \multirow{2}{*}{$\begin{array}{l}\text { Nepal } \\
\text { Pokhara Regional } \\
\text { n (\%) }\end{array}$} & \multicolumn{2}{|l|}{ Tanzania } & \\
\hline & $\begin{array}{l}\text { Azimpur Tertiary } \\
\text { n (\%) }\end{array}$ & $\begin{array}{l}\text { Kushtia District } \\
\text { n (\%) }\end{array}$ & & $\begin{array}{l}\text { Temeke Regional } \\
\text { n (\%) }\end{array}$ & $\begin{array}{l}\text { Muhimbili National } \\
\text { n (\%) }\end{array}$ & \\
\hline Total & 2910 & 2412 & 7370 & 6748 & 3575 & 23,015 \\
\hline \multicolumn{7}{|l|}{ Woman's Age } \\
\hline$<18$ years & $25(0.9)$ & $3(0.1)$ & $311(4.2)$ & $26(0.4)$ & $8(0.2)$ & $373(1.6)$ \\
\hline 18-19years & $475(16.3)$ & $197(8.2)$ & $817(11.1)$ & 767 (11.4) & $159(4.4)$ & $2415(10.5)$ \\
\hline 20-24 years & $1158(39.8)$ & 954 (39.6) & $3080(41.8)$ & $2314(34.3)$ & $722(20.2)$ & 8228 (35.8) \\
\hline 25-29years & 867 (29.8) & $736(30.5)$ & $2114(28.7)$ & $1697(25.1)$ & $1134(31.7)$ & $6548(28.5)$ \\
\hline 30-34 years & $297(10.2)$ & $373(15.5)$ & $827(11.2)$ & $1146(17)$ & $924(25.8)$ & $3567(15.5)$ \\
\hline $35+$ years & $88(3)$ & $149(6.2)$ & $221(3)$ & $798(11.8)$ & $628(17.6)$ & $1884(8.2)$ \\
\hline \multicolumn{7}{|l|}{ Woman's education } \\
\hline No education & $39(1.3)$ & $77(3.2)$ & $268(3.6)$ & $202(3)$ & $66(1.8)$ & $652(2.8)$ \\
\hline Primary incomplete & $111(3.8)$ & $127(5.3)$ & $252(3.4)$ & $81(1.2)$ & $45(1.3)$ & $616(2.7)$ \\
\hline Primary complete & $339(11.6)$ & $347(14.4)$ & $302(4.1)$ & $31(0.5)$ & $5(0.1)$ & $1024(4.4)$ \\
\hline Secondary incomplete & $985(33.8)$ & 954 (39.6) & $1637(22.2)$ & $4053(60.1)$ & $1299(36.3)$ & 8928 (38.8) \\
\hline Secondary complete or higher & $1273(43.7)$ & $870(36.1)$ & $4509(61.2)$ & $2346(34.8)$ & $2146(60)$ & $11,144(48.4)$ \\
\hline Don't know & $163(5.6)$ & $37(1.5)$ & $402(5.5)$ & $35(0.5)$ & $14(0.4)$ & $651(2.8)$ \\
\hline \multicolumn{7}{|l|}{ Parity } \\
\hline Nullipara & $1350(46.4)$ & $1038(43)$ & $4402(59.7)$ & $2917(43.2)$ & $1363(38.1)$ & $11,070(48.1)$ \\
\hline Multipara & $1504(51.7)$ & $1369(56.8)$ & $2961(40.2)$ & $3816(56.6)$ & $2207(61.8)$ & $11,857(51.5)$ \\
\hline Missing & $56(1.9)$ & $5(0.2)$ & $7(0.1)$ & $15(0.2)$ & $5(0.2)$ & $88(0.4)$ \\
\hline \multicolumn{7}{|l|}{ Mode of birth } \\
\hline Normal vaginal birth & $767(26.4)$ & $1364(56.6)$ & $5840(79.2)$ & $6184(91.6)$ & $1506(42.1)$ & $15,661(68)$ \\
\hline $\begin{array}{l}\text { Vaginal births: Breech, } \\
\text { Vacuum/Forceps }\end{array}$ & $1(0)$ & $0(0)$ & $349(4.8)$ & $10(0.1)$ & $9(0.2)$ & $369(1.6)$ \\
\hline Caesarean Section & $2119(72.8)$ & $972(40.3)$ & $1140(15.5)$ & $472(7.0)$ & $1995(55.8)$ & $6698(29.1)$ \\
\hline \multicolumn{7}{|l|}{ Estimated Blood Loss at birth } \\
\hline Normal: $\leq 500 \mathrm{mls}$ & $2792(97.2)$ & $2236(95.9)$ & $6993(95.6)$ & $6289(96.2)$ & $3026(90.1)$ & $21,336(95.2)$ \\
\hline PPH: $>500-\leq 1000 \mathrm{mls}$ & $48(1.7)$ & $63(2.7)$ & $133(1.8)$ & $157(2.4)$ & $243(7.2)$ & $644(2.9)$ \\
\hline Severe PPH > $1000 \mathrm{mls}$ & $6(0.2)$ & $11(0.5)$ & $3(0.04)$ & $12(0.2)$ & $12(0.4)$ & $44(0.2)$ \\
\hline Missing & $26(0.9)$ & $22(0.9)$ & $185(2.5)$ & $80(1.2)$ & $79(2.4)$ & $392(1.8)$ \\
\hline
\end{tabular}




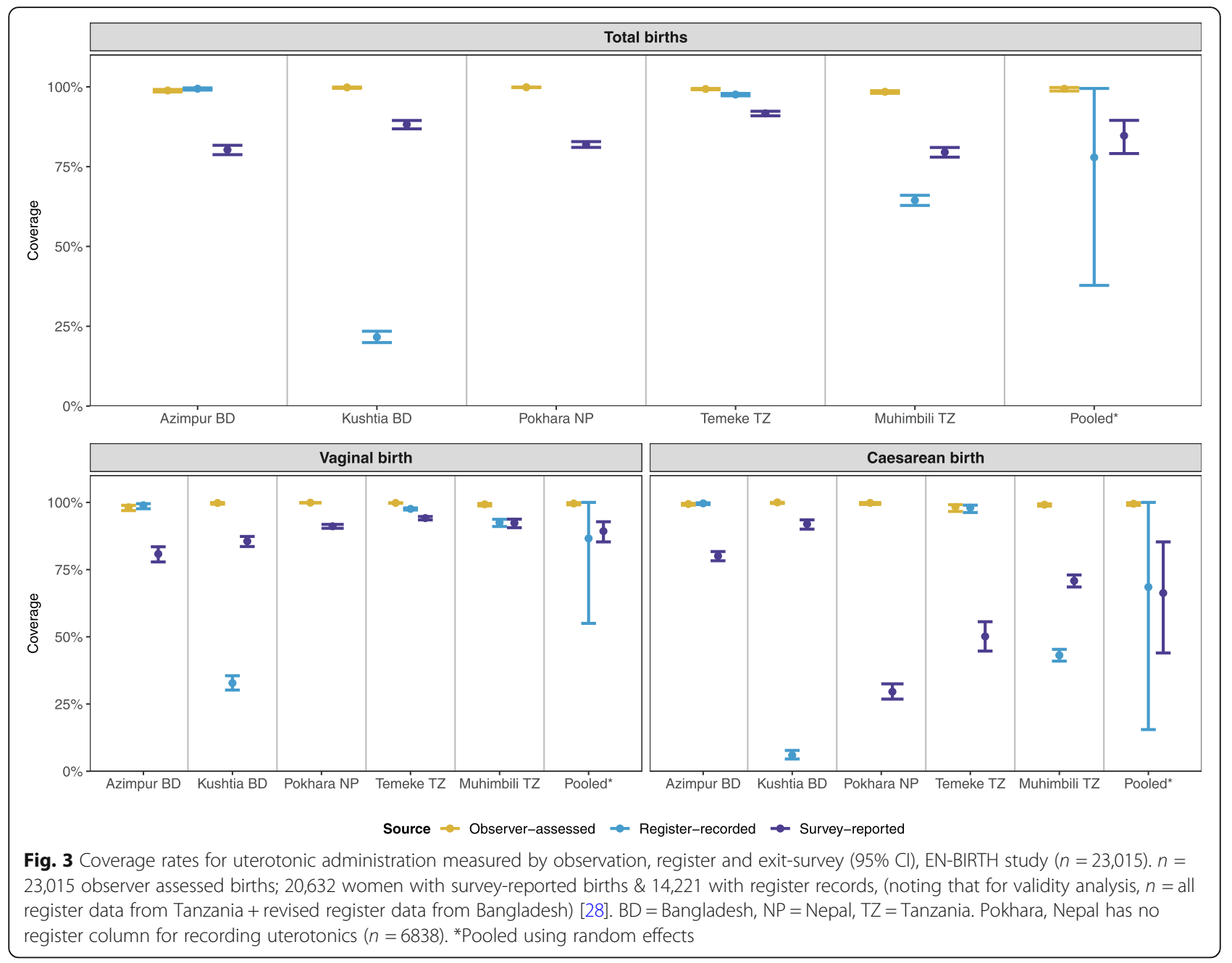

receiving uterotonics compared with women who gave birth by caesarean (Fig. 3). Survey-reported coverage for vaginal births was $89.3 \%$ (96\% CI 85.3-92.8) overall and ranged from $80.8 \%$ in Azimpur BD to $94.1 \%$ in Temeke TZ. For caesarean births survey-reported coverage was
66.3\% (95\% CI 44.0-85.3) and ranged from 50.2\% in Temeke TZ to $92 \%$ in Kushtia BD (Additional file 9). The largest differential between survey-reported uterotonic coverage was in Pokhara NP where observerassessed coverage was $99.9 \%$ (95\% CI $99.8-100 \%)$

\begin{tabular}{|c|c|c|c|c|c|c|c|c|}
\hline & \multicolumn{2}{|c|}{ Bangladesh } & \multirow{2}{*}{$\begin{array}{c}\text { Nepal } \\
\text { Pokhara } \\
\text { Nepal }\end{array}$} & \multicolumn{2}{|c|}{ Tanzania } & \multicolumn{3}{|c|}{ Facilities Combined ${ }^{*}$} \\
\hline & $\begin{array}{c}\text { Azimpur } \\
\text { Tertiary }\end{array}$ & $\begin{array}{l}\text { Kustia } \\
\text { District }\end{array}$ & & $\begin{array}{c}\text { Temeke } \\
\text { District }\end{array}$ & $\begin{array}{c}\text { Muhimbili } \\
\text { District }\end{array}$ & $\begin{array}{l}\text { Vaginal } \\
\text { Births }\end{array}$ & $\begin{array}{c}\text { Caesarean } \\
\text { Births }\end{array}$ & $\begin{array}{c}\text { All } \\
\text { Births }\end{array}$ \\
\hline Mother given any medicine immediately after birth of the baby & 14.4 & 2.1 & 11.5 & 5.1 & 13.1 & 3.4 & 24.2 & 9.6 \\
\hline Mother given uterotonic immediately after birth of the baby & 14.4 & 2.1 & 12.5 & 5.1 & 13.3 & 3.2 & 26.0 & 8.7 \\
\hline Type of uterotonic (Oxytocin, Ergometrine, Misoprostol, \& other) & 1.8 & 15 & 5.8 & 0.5 & 8.6 & 4.9 & 5.9 & 5.2 \\
\hline When were the injection/tablets given? & 5.3 & 26.8 & 4.5 & 6.8 & 12.8 & 5.5 & 13 & 7.6 \\
\hline How was it given? & 0.2 & 1 & 0.9 & 0.1 & 0.8 & 0.5 & 0.9 & 0.6 \\
\hline \multicolumn{9}{|l|}{ Don't Know Responses: } \\
\hline \multicolumn{9}{|l|}{$>20 \%:$ Poor } \\
\hline \multicolumn{9}{|l|}{$15.1-20 \%:$ Moderate } \\
\hline \multicolumn{9}{|l|}{ 10.1-15\%: Good } \\
\hline \multicolumn{9}{|l|}{ 5.1-10\% : Very Good } \\
\hline \multicolumn{9}{|l|}{ 0-5\% : Excellent } \\
\hline
\end{tabular}


compared with 91.1\% (95\% CI 90.4-91.8) survey-reported for vaginal births, and $29.6 \%$ (95\% CI 26.8-32.5) surveyreported for caesarean births (Additional file 9).

Women who had a caesarean section were more likely to report "don't know" for any uterotonic indicator than those with vaginal birth. "Don't know" replies were highest (>20\%) for women with caesarean births reporting on medication administration immediately after birth (Fig. 4).

Descriptive analysis comparing reported coverage of potential combined uterotonic indicator options with observed coverage, showed no difference between the various combinations (Additional file 7).

\section{Register-recorded findings}

For hospitals with a specific column, register-recorded uterotonic coverage was $77.9 \%$ (95\% CI 37.8-99.5) and ranged from 21.6\% (Kushtia, BD) to 99.4\% (Azimpur, BD). Registerrecorded coverage was lowest in Pokhara NP where this data element is not captured (Fig. 5 and Additional file 10). When capturing uterotonics, register-recorded coverage estimates were higher for vaginal births $(86.6,95 \%$ CI 55.0-100.0) than caesareans (68.5, 95\% CI 15.5-100.0).

Percent agreement between register-recorded and observer-assessed coverage was higher with not recorded results excluded: $86.1 \%$ (95\% CI 48.5-100.0) for all modes of birth combined, compared to $77.2 \%$ (95\% CI 37.7-99.3) when not-recorded results were included as 'not given' (Additional file 10). Positive predictive value was $>99 \%$ for all modes of birth (Additional file 10).

Descriptive analysis of the Bangladesh specific results found that register-recorded coverage of uterotonic administration increased with the introduction of revised registers that included a specific column for third stage labour management. In Azimpur there was an $81.6 \%$ increase in the number of register-recorded cases, and 21.6\% increase in Kushtia (Additional file 11).

\section{Objective 2: Denominator comparison}

Uterotonic coverage was over-estimated using the live birth denominator in all EN-BIRTH hospitals, the absolute difference ranged between -1.3 and $-6.8 \%$, and relative difference ranged from -0.1 to 0 (Table 2).

\section{Objective 3: Gaps analysis for coverage and quality of care, and measurement}

The coverage gap for oxytocin for $\mathrm{PPH}$ prevention within $30 \mathrm{~min}$ of birth was small (1.9\%) in all sites (Fig. 6). Quality gap analysis showed timing distribution was different between each hospital and by mode of birth (Additional file 12). Oxytocin was administered more quickly for caesarean births than vaginal births, and overall most women $(88.8 \%$ Azimpur, $90.3 \%$ Kushtia, 68.6\% Pokhara, 52.4\% Temeke and 76.7\% Muhimbili) received oxytocin within $3 \mathrm{~min}$ (the "right time", Fig. 7). The distribution of Oxytocin dose, "right content", showed that $66.3 \%$ of women received $10 \mathrm{IU}$ of Oxytocin, 21.8\% $20 \mathrm{IU}, \quad$ and $4.25 \% \quad 40 \mathrm{IU}$ (Additional file 13). Of those who received $40 \mathrm{IU}, 2.2 \%$ were observed to have a blood loss of $>500 \mathrm{mls}$ (Additional file 14). Women giving birth via caesarean section were more likely to receive higher doses of Oxytocin than those with vaginal births. In observed

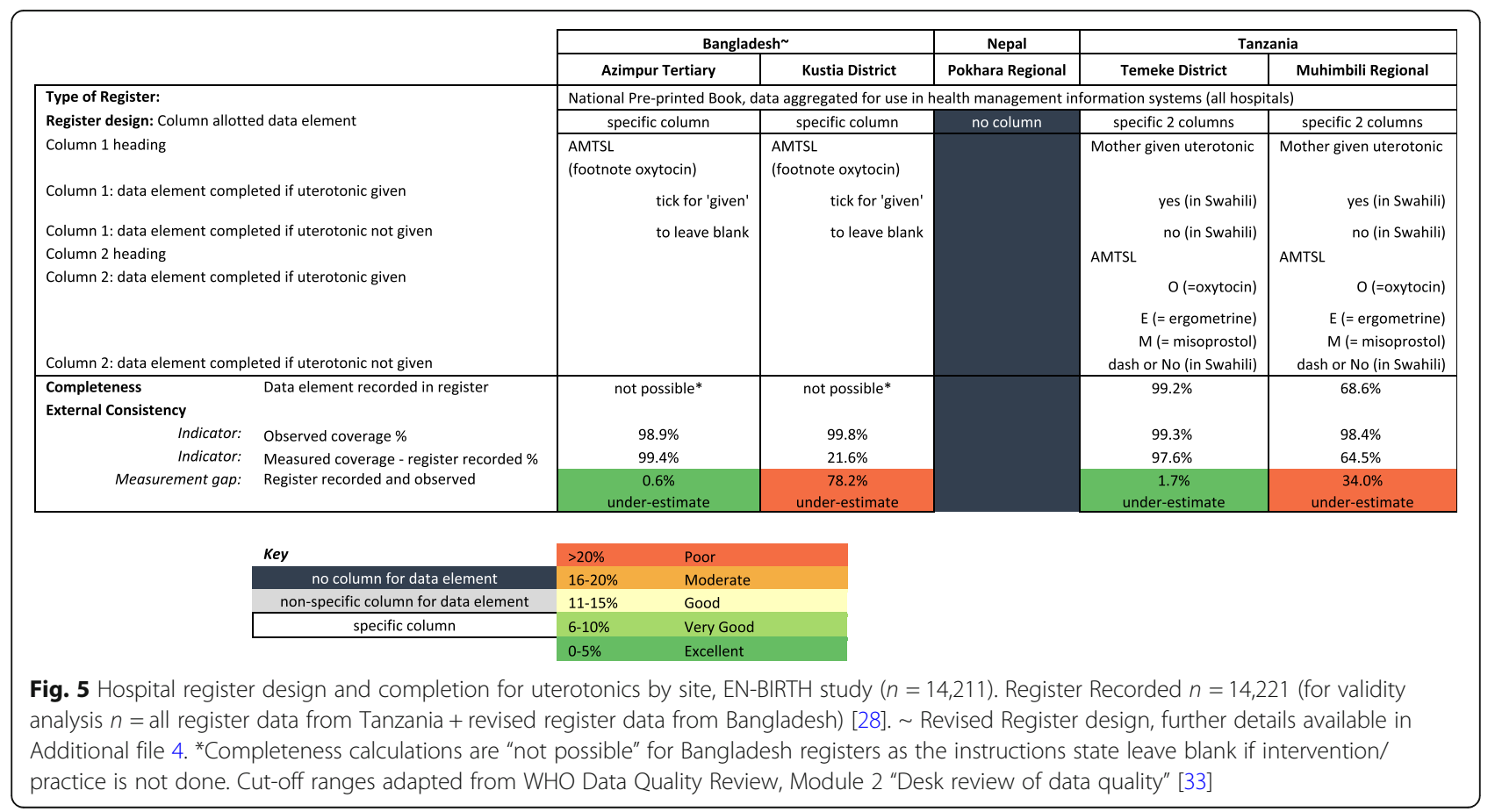


Table 2 Denominator comparisons for uterotonic indicator, EN-BIRTH study $(n=23,015)$

\begin{tabular}{|c|c|c|c|c|c|}
\hline & \multicolumn{2}{|l|}{ Bangladesh } & \multirow{2}{*}{$\frac{\text { Nepal }}{\text { Pokhara Regional }}$} & \multicolumn{2}{|l|}{ Tanzania } \\
\hline & Azimpur Tertiary & Kushtia District & & Temeke Regional & Muhimbili National \\
\hline Number of women who gave birth & 2910 & 2412 & 7370 & 6748 & 3575 \\
\hline Uterotonic observed given & 2858 & 2333 & 7221 & 6653 & 3485 \\
\hline Total births & 2936 & 2459 & 7442 & 6869 & 3765 \\
\hline Live births & 2896 & 2308 & 7175 & 6634 & 3509 \\
\hline $\begin{array}{l}\text { Uterotonic coverage among women who } \\
\text { gave birth (\%) }\end{array}$ & 98.9 & 99.8 & 99.9 & 99.3 & 98.4 \\
\hline $\begin{array}{l}\text { Uterotonic coverage using live birth } \\
\text { denominator }(\%)\end{array}$ & 98.7 & 101.1 & 100.6 & 100.3 & 99.3 \\
\hline $\begin{array}{l}\text { Uterotonic coverage using all birth } \\
\text { denominator (\%) }\end{array}$ & 97.3 & 94.9 & 97.0 & 96.9 & 92.6 \\
\hline Relative difference \% & 0.0 & -0.1 & 0.0 & 0.0 & -0.1 \\
\hline Absolute difference \% & -1.3 & -6.2 & -3.6 & -3.4 & -6.8 \\
\hline
\end{tabular}

Legend: $N=23,051$ women observed to give birth

Uterotonic coverage is calculated using number of women who gave birth (rather than "all" or "live" births)

cases, the route of administration was intramuscular (IM) for $65.2 \%$, and intravenous (IV) in $34.3 \%$ of births (Additional file 8).

The measurement gap was $18.1 \%$ for register-recorded and $6 \%$ for survey-reported coverage. For women who had a vaginal birth, 39\% (ranging from $0.7 \%$ in Azimpur to $67.6 \%$ at Temeke) could report the purpose of the uterotonic medication ('to prevent haemorrhage'). For caesarean births, this dropped to $6.9 \%$ (ranging from $0.3 \%$ in Azimpur to $17.1 \%$ in Temeke) (Additional file 8 ). Less than $2.5 \%$ of women could name the drug they were given (Additional file 8).

\section{Objective 4: Barriers and enablers to data collection}

We identified three categories under which to group emerging themes regarding barriers and enablers to routine recording of uterotonic administration in hospital registers: 1) Register or system design; 2) Register filling or completion; 3) Register use (Fig. 8) [32].

\section{Register or system design}

Within this category, two themes emerged for uterotonic recording. Focus group participants talked about the complexity of health data systems and the specific register design for uterotonics. Across all sites, health workers identified multiple places where they were expected to document information about care during the third stage of labour, including the register, clinical records, partograph, and drug chart. Many staff reported they did not know who would be taking primary responsibility for documentation (Additional files 15 and 16).

These challenges were underlined in Kushtia BD and Muhimbili TZ, where register performance was lower:
'She will go to the nursing station to do her documentation in the health management system tool, then fills the midwifery book, the books are in different places and are far from the patient and the delivery room.'

-Health worker, Muhimbili TZ

Participants reported that design of the register, amount of space and inclusion of a specific column for the uterotonic documentation is needed to facilitate high quality data collection:

'There is no such space to record, maybe we have administered a certain amount of oxytocin or ergometrine, no space for that.'

-Data collector, Muhimbili TZ

\section{Register filling or completion}

Lack of health workers (quantity and capacity) was identified as a critical challenge throughout all the focus group discussions and was a key barrier to uterotonic data collection among other indicators:

'We have a shortage of manpower and time ... We need time to examine and provide the treatment thoroughly... But also we have to maintain the documentation.'

-Health worker, Azimpur BD

Evidence from Temeke TZ suggests that some of these challenges can be addressed with good organisation of workspaces to ensure that clinical environments are enabling with the required register books, computers, and stationary positioned in convenient clinical locations 

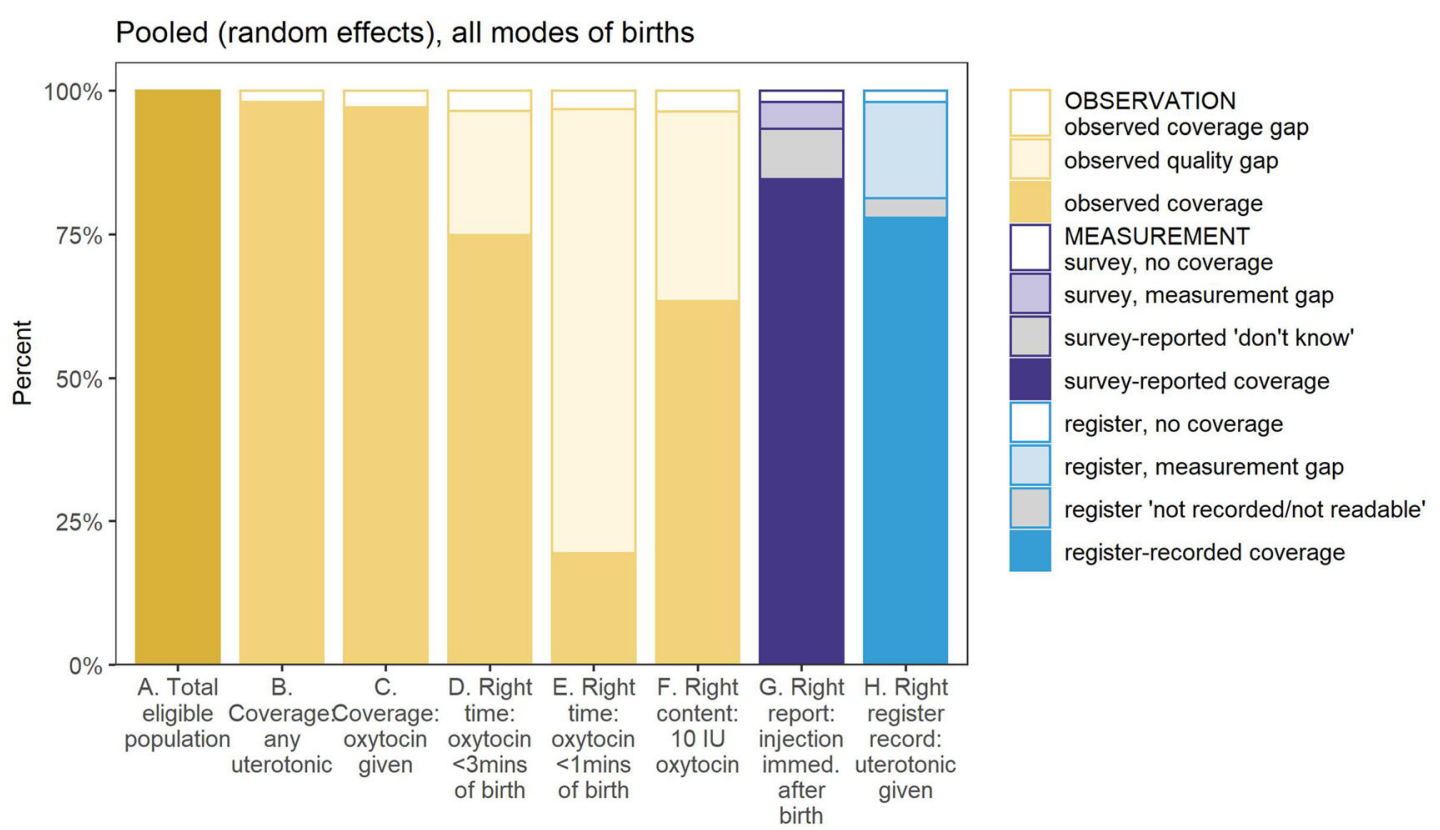

\section{All modes of birth}

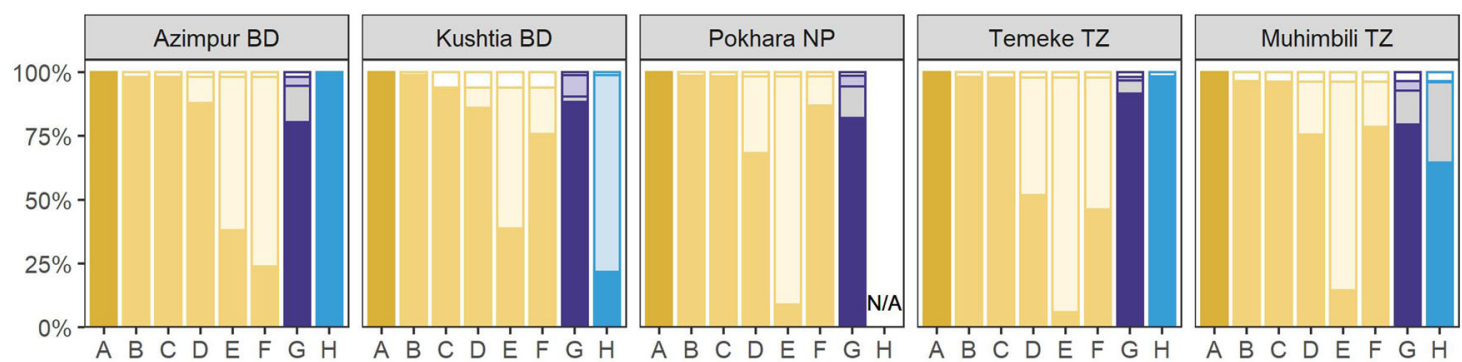

Vaginal birth
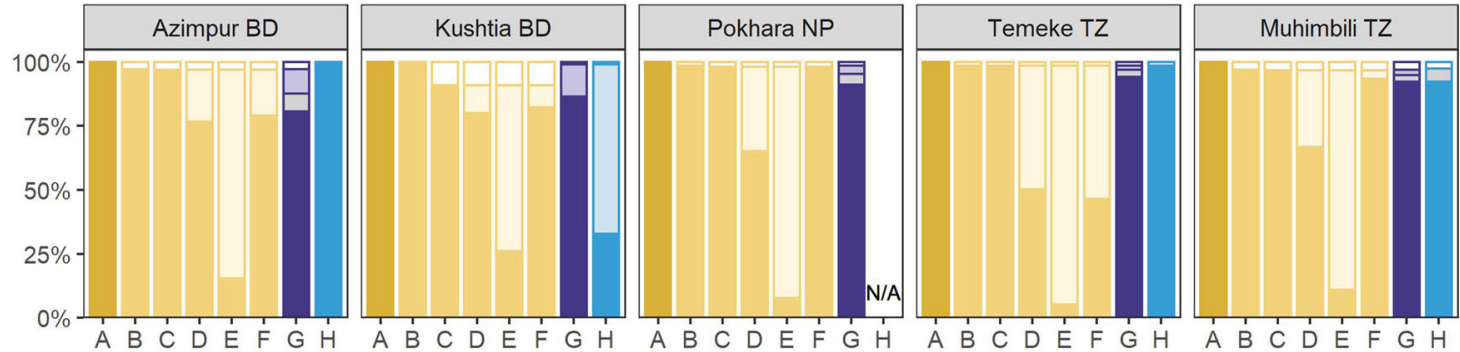

Caesarean birth
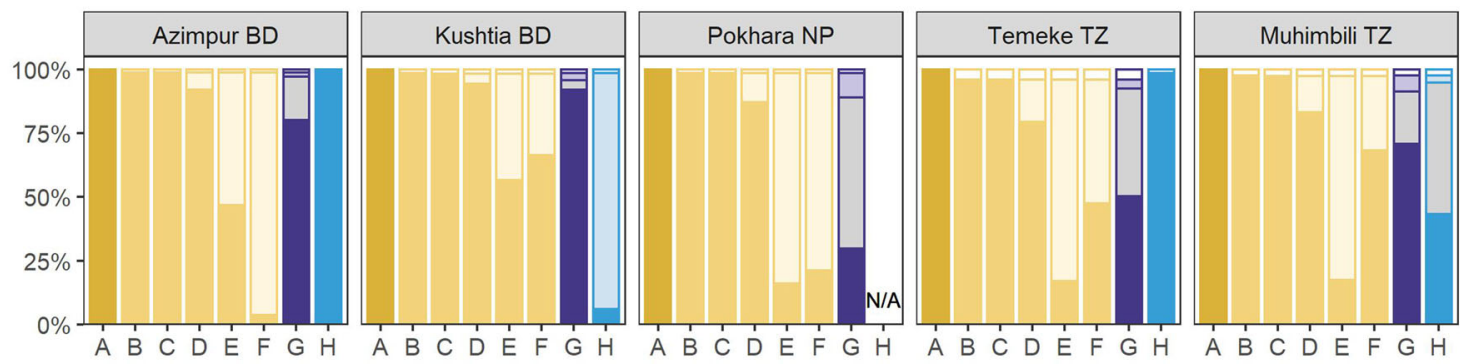

Fig. 6 Gap analysis for uterotonic coverage and quality, EN-BIRTH study. $N=23,015$ observer assessed births: 20,632 survey reported births and 14,221 register recorded (all cases in Tanzania and those from revised register data from Bangladesh) BD = Bangladesh, NP= Nepal, TZ=Tanzania 


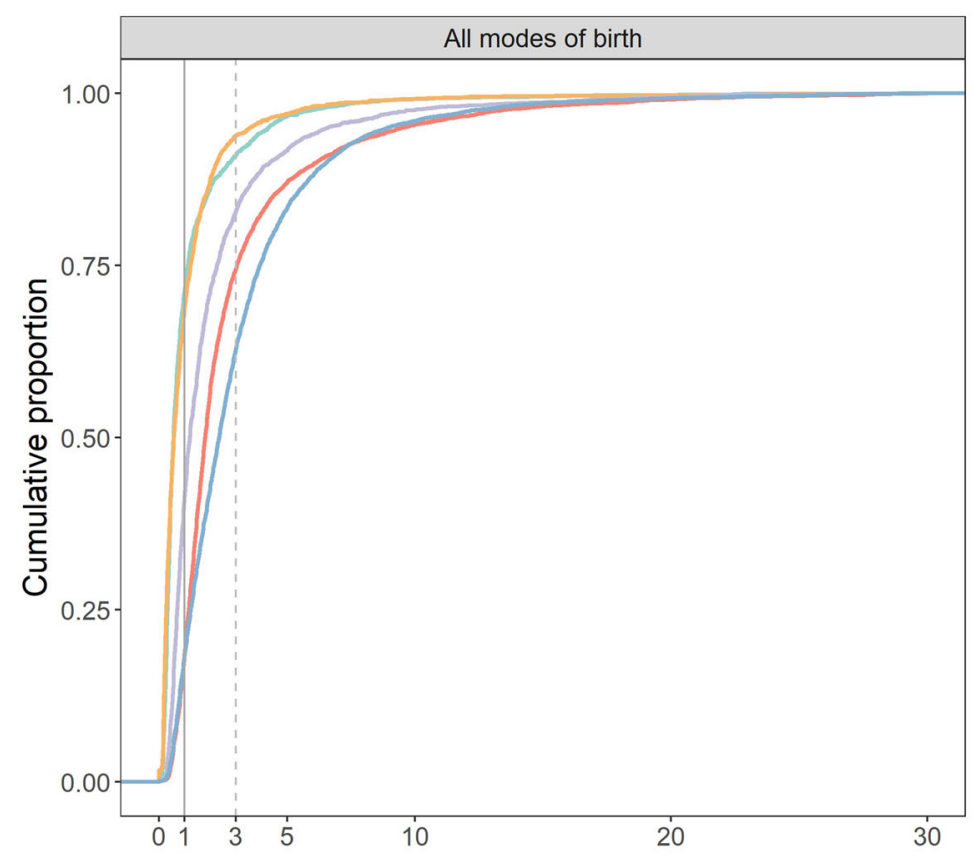

Site

- Azimpur BD

- Kushtia BD

- Muhimbili TZ

- Pokhara NP

- Temeke TZ

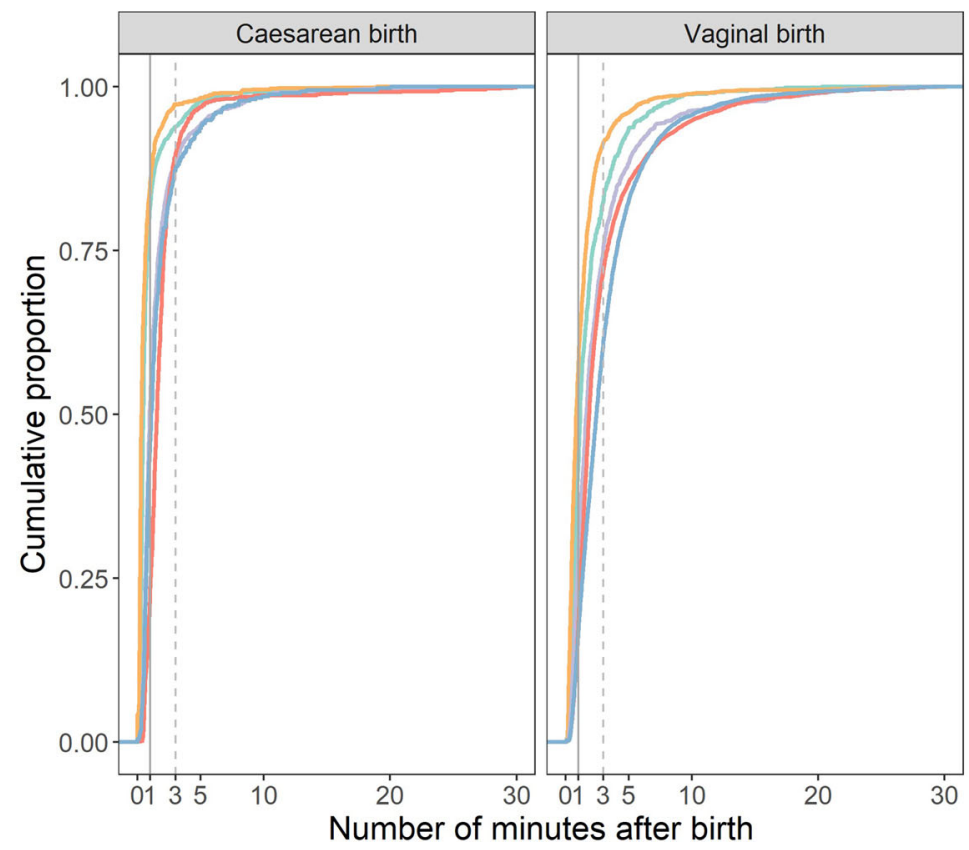

Site

- Azimpur BD

- Kushtia BD

- Muhimbili TZ

- Pokhara NP

- Temeke TZ

Fig. 7 Timing of oxytocin administration, EN-BIRTH study $(n=22,121) . N=22,121$ (women observer-assessed to receive oxytocin from 0 to 30 min after birth). BD = Bangladesh, NP = Nepal, TZ = Tanzania

that facilitate health workers to remain near service users:

'There is a specific place kept and arranged for documenting all the provided care ... they are supposed to be there, equipment like books for recording and pens [are there], and it is not far'

-Data collector, Temeke TZ
Healthcare staff reported that they are usually completing care during the third stage of labour and documentation simultaneously. Staff from Kushtia and Muhimbili identified the location of registers as problematic, which was also identified as a registerrecording barrier, across all sites, for women giving birth in the operating theatres Fig. 8.

Participants from Kushtia BD and Muhimbili TZ reported supply challenges with basic equipment 


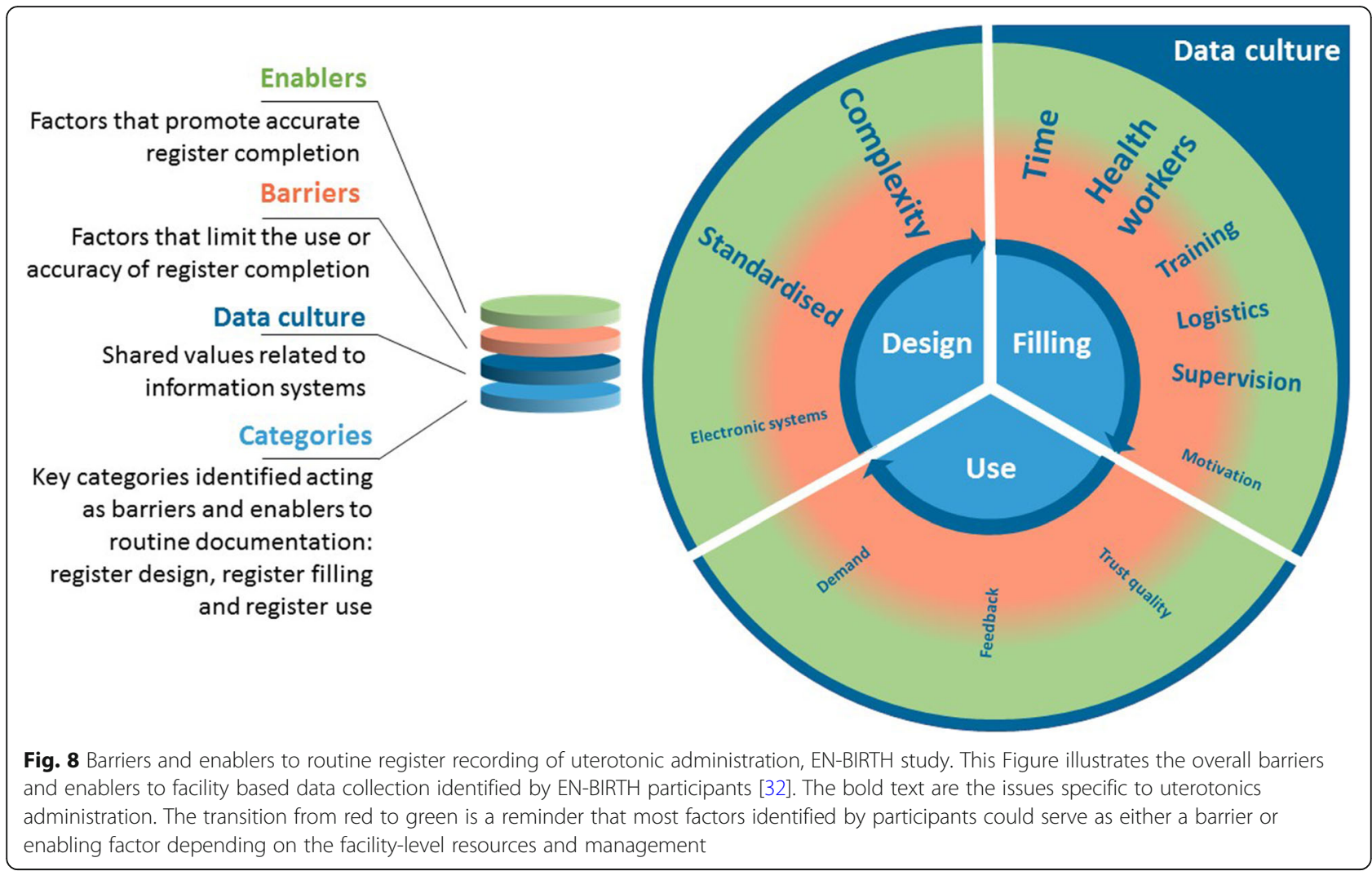

including multiple register stock-outs in Kushtia, and the requirement for staff to supply their own pens:

'We usually buy our pen ourselves, we do not get a pen from the office.'

-Health worker, Kushtia BD

\section{Register use}

Respondents from Temeke $\mathrm{TZ}$ and Azimpur BD reported these sites have instituted regular opportunities for staff to use and reflect on their data. Moreover, staff in these hospitals were using data for a variety of purposes in their own practice:

'These documents show what the patient is suffering from and what medication is given ... Also these documents are important for research works, planning, improving health services, helping secure you in the court, and in statistics. The documents are very important in improving health services.'

-Data collector, Temeke TZ

Feedback was consistently valued by staff in all hospitals, and health workers suggested leadership was an enabling factor for documentation. Temeke TZ had highly accurate register reporting for uterotonics. Staff reported being well-supported by management with regular feedback, training and opportunities to use their data during budget planning, stock management, audit and monitoring:

'Leadership in general from the lower level to the upper level should have good communication and cooperation to ensure that everything is well documented and records are kept with good quality.' -Data collector, Temeke TZ

Staff from EN-BIRTH sites with more accurate register-recording of uterotonic coverage reported training as an essential component. Managerial gaps and lack of training were cited as barriers to documentation in Kushtia, the site with lowest performing registerrecording.

'However we are not well trained'.

-Health worker, Kushtia BD

\section{Discussion}

Postpartum haemorrhage remains a leading cause of preventable maternal mortality. Despite WHO recommendations for universal access to prophylactic uterotonics, there are no nationally representative data to track coverage and quality of this intervention $[6,7]$. EN-BIRTH is the largest measurement validation study 
to date, with more than 10 times the number of participants of previous studies, and assessed both surveyreported and register-recorded indicators.

Survey-reported data for assessing uterotonic coverage was problematic, with high "don't know" replies for caesarean births, and lower accuracy than the better performing registers. Our findings align with previous validation studies suggesting low individual-level accuracy for survey measures of uterotonic coverage [20-24]. There was also poor consistency between observerassessed and survey-reported events around timing, and type of uterotonic administration. Our survey data was collected at exit-interview on discharge from the hospital; and we anticipate that the discrepancy between woman's report and gold standard data may increase over time in line with other study findings [20-24].

Our results underline that accurate report in surveys is challenging for events around the time of birth, especially for women receiving more complex clinical care (e.g. PPH management or caesarean section). This is unlikely to be recall alone; the women's knowledge will depend on the quality of information provided by healthcare staff, and if informed consent was elicited [20, 24]. Indicators regarding knowledge of care and rationale could serve as tracers for respectful care, as women have a right to informed decision making and autonomy [34, 35]. These rights are increasingly recognised: respectful and dignified care was the number one demand from the recent 'what women want' campaign with $>1$ million participants across 114 countries [36]. Participants experiencing caesareans were less likely to report that the health worker explained the purpose of uterotonic medication (Additional file 8). Given caesarean section rates are increasing globally [37], further research is needed on how accuracy of women's report is effected by both direct (anaesthetics or sedatives) and indirect processes. This includes what information is given to women about treatment of them and their baby, and issues around gaining her informed consent.

Register completion varies [7, 20, 27, 38-41]. The two highest performing hospitals achieved high sensitivity (97.6-99.5\%) and percent agreement (97.3-99.0\%) between register-recorded and observer-assessed coverage. Pokhara NP had no column or space available in the register for uterotonic documentation. These findings draw attention to the requirement for clear register design around priority measures and the need for more global guidance and standardisation, especially given there are multiple stakeholders and only limited space and capacity for the inclusion of data elements in routine registers. Wider use of national electronic HMIS tools, such as District Health Information Software 2 (DHIS2) [42, 43], provide important platforms for faster uptake. Evidence from Nigeria suggests that tracking of maternal and newborn indicators through HMIS is possible with strong multi-partner collaboration at all levels of the health system to rationalise data flow, and provide supervision with data quality review, feedback and data reporting [27].

Register design is necessary but not sufficient to achieve high quality data, inclusive training and implementation strategies are also imperative. Despite sharing the same register design and layout, results differed between Temeke and Muhimbili TZ, and between Azimpur and Kushtia BD after implementation of the new national register. Our results support evidence that data collection and management processes represent a heavy workload for health workers [39, 44-46], who face competing priorities and challenges on their time. Managerial support for data collection including supervision, feedback and review are therefore essential [27].

Maternal mortality remains high in many settings despite good coverage of facility births [47]; this divergence in expectation is usually attributed to quality gaps in service provision. Yet to be sure, we need more granular data on the content and quality of care. There was a quality gap for timing with less than $20 \%$ of women receiving oxytocin within 1 minute of birth as recommended by WHO [5], although the majority were within $\leq 3 \mathrm{~min}$ (Fig. 7). We recommend further research around the precise timing need for uterotonic administration [48], especially as early indications from an ongoing trial assessing tranexamic acid to treat PPH, suggest that the positive effect of administration reduces with every minute of delay [49].

Uterotonic coverage was high in our study sites, although these high caseload referral centres are not representative of all facilities in LMICs. Several studies indicate that quality of care is lower in primary-level facilities, especially those with a low case-load [47]. We used the elements of timing, and dose of drug use as quality measures. However, Oxytocin is light and heat sensitive and should be stored between 2 and $8{ }^{\circ} \mathrm{C}$ for extended shelf life [5]. Stock-outs, poor adherence to manufacturer guidelines and prolonged exposure to high temperatures reduce the availability of effective Oxytocin at the point of care [50]. Oxytocin samples tested from multiple LMICs were found to have insufficient active ingredient, with up to $74 \%$ of tested samples failing $[51,52]$. Given this would likely fall outside routine measurement systems, further work to examine these aspects of quality are needed.

Denominators are crucial for public health decisionmaking [53]. Worldwide, four in every five births are estimated to be taking place in facilities and almost $81 \%$ are supported by a skilled birth attendant, but the poorest women in the poorest countries are still without access $[1,25]$. Whilst most of the numerator of women given injectable uterotonics may be captured in a facility 
(given this is WHO policy), a denominator of only facility births omits home births [16]. Some countries do have a policy supporting misoprostol use for non-facility births, but these data are not currently being measured. Many LMICs estimate denominators via census-derived population estimates (i.e. for immunisation) [54]. This is also feasible using an estimated total birth denominator for a given population, such as a district. If there are many births in the private sector, HMIS should aim to include the count data of women given uterotonics and the relevant denominator. In India, the private and nonprofit sectors are now mandated to report selected data to the government HMIS $[54,55]$.

\section{Strengths and limitations}

EN-BIRTH study strengths include use of direct observation as gold standard, the large number of participants, time-stamped data, stratification of results by mode of birth, and five differing hospitals from three LMICs. Unfortunately, even the high number of observed births were not able to mitigate statistical challenges validating indicators with high prevalence, especially those only calculated for observations with $\geq 10$ counts in each column of the $2 \times 2$ tables to assess sensitivity, specificity, inflation factor and area under the curve [56]. The gold standard could also be susceptible to errors in data recording and interpretation, especially for estimated blood loss. Some of these risks were reduced via use of the custom-built tablet-based application, standardised training, and supervision throughout data collection. We also assessed inter-observer error by double entering observations for $5 \%$ of cases, and found good agreement for uterotonics (Additional file 6). Study data were collected in $\mathrm{CEmOC}$ level hospitals where higher case-loads, access to multidisciplinary teams, and potentially higher levels of supervision and training might mean that both the provision and recording of uterotonic drugs are completed to a higher standard. The Hawthorne effect (whereby a study changes practice) could have resulted in improved register documentation and/or uterotonic provision by health workers. However, comparison of registers pre-study with duringafter register records shows no significant change in completeness or documentation practises [28].

\section{Research gaps for improving measurement}

Systematic research and investment in implementation are needed to improve register design and use. Where coverage is high, a simple uterotonics coverage indicator might be insufficient to drive quality improvement. Other measures may be required such as health facility assessments regarding drug quality, and stock management, or use of specific audits. There is potential for linking databases (such as survey and facility-based data) but this may require special studies and complex analyses [6, 57-60].

Assessment of data flow within HMIS and interoperability with related platforms, such as supply logistics systems, are also needed. This could be undertaken as part of a feasibility assessment of maternal and newborn HMIS tool kits in a range of LMICs and humanitarian settings. It should include data quality assessments at different levels of the HMIS, including costs for data collection and assessment of usefulness to policymakers.

\section{Conclusions}

EN-BIRTH findings for uterotonics measurement are compatible with existing evidence suggesting that asking women about clinical interventions during or immediately after birth is unreliable [20-24], especially following caesarean section. Based on this evidence, we do not recommend the addition of a uterotonic indicator to household survey platforms such as DHS and MICS. Registers have potential to accurately capture coverage of uterotonics and could provide timely data; however, this requires work on register design, standardisation and improved global guidance. A welldesigned, parsimonious, standardised register is necessary but not sufficient to collecting consistent highquality data. Importantly, those who enter the data are often over-worked health professionals who need to know why these data matter for their own use, and for the women they care for. Feedback mechanisms and data use are important enablers to drive improvements in register-recording practices.

\section{Supplementary Information}

Supplementary information accompanies this paper at https://doi.org/10. 1186/s12884-020-03420-X.

Additional file 1. Summary of previous validation for measures of uterotonic administration.

Additional file 2. Ethical approval of local institutional review boards, EN-BIRTH study.

Additional file 3. STROBE Checklist.

Additional file 4. Data collection dates by site, EN-BIRTH study.

Additional file 5. Facility register design and completion approaches for uterotonics by site, EN-BIRTH study $(n=22,002)$.

Additional file 6. Inter-observer agreement for uterotonic administration using Kappa, EN-BIRTH study.

Additional file 7. Survey- reported uterotonic indicator combinations compared with observer-assessed coverage, EN-BIRTH study.

Additional file 8. Descriptive uterotonic coverage data: observerassessed, exit-survey reported and register-recorded findings, EN-BIRTH study $(n=23,015)$.

Additional file 9. Individual-level validation of exit-survey report for uterotonic administration, EN-BIRTH Study ( $n=23,051)$.

Additional file 10. Individual-level validation of register recording for uterotonic administration, EN-BIRTH study $(n=15,645)$. 
Additional file 11. Comparison of uterotonic coverage measurement using original and revised Bangladesh registers, EN-BIRTH study ( $n=$ 5207).

Additional file 12. Association testing for timing of Oxytocin administration, EN-BIRTH Study $(n=22,121)$.

Additional file 13. Oxytocin dose by EN-BIRTH site and mode of birth, EN-BIRTH study $(n=22,269)$.

Additional file 14. Estimated Blood Loss (EBL) compared with Oxytocin coverage, EN-BIRTH Study.

Additional file 15. Assessment of routine recording responsibilities for uterotonic provision, EN-BIRTH Study.

Additional file 16. Register recording order and prioritisation for uterotonic provision, EN-BIRTH study.

\begin{abstract}
Abbreviations
AMTSL: Active management of the third stage of labour; BD: Bangladesh; CEmOC: Comprehensive emergency obstetric care; CIFF: Children's Investment Fund Foundation; DHS: Demographic and Health Surveys Program; DHIS2: District Health Information Software 2; EN-BIRTH: Every Newborn-Birth Indicators Research Tracking in Hospitals study; EPMM: Ending Preventable Maternal Mortality; HMIS: Health Management Information Systems; icddr,b: International Centre for Diarrheal Disease Research, Bangladesh; IHI: Ifakara Health Institute; IM: Intramuscular; IU: International units; LMIC: Low and Middle Income Country; LSHTM: London School of Hygiene \& Tropical Medicine; MUHAS: Muhimbili University of Health and Allied Sciences; MICS: Multiple Indicator Cluster Survey; NP: Nepal; PPH: Postpartum Haemorrhage; PRISM: Performance of Routine Information System Management; TZ: Tanzania; WHO: World Health Organization
\end{abstract}

\section{Acknowledgements}

Firstly, and most importantly, we thank the women, their families, the health workers and data collectors. We credit the inspiration of the late Godfrey Mbaruku. We thank Claudia DaSilva, Veronica Ulaya, Mohammad Raisul Islam, Sudip Karki and Rabina Sarki for their administrative support and Sabrina Jabeen, Goutom Banik, Md. Shahidul Alam, Tamatun Islam Tanha and Md. Mohsiur Rahman for support during data collectors training. We acknowledge the following groups for their guidance and support. National Advisory Groups:

Bangladesh: Mohammod Shahidullah, Khaleda Islam, Md Jahurul Islam. Nepal: Naresh P KC, Parashu Ram Shrestha.

Tanzania: Mohammod Bakari Kambi, Georgina Msemo, Asia Hussein, Talhiya Yahya, Claud Kumalija, Eliudi Eliakimu, Mary Azayo, Mary Drake, Honest Kimaro.

\section{EN-BIRTH validation collaborative group}

Bangladesh: Md. Ayub Ali, Bilkish Biswas, Rajib Haider, Md. Abu Hasanuzzaman, Md. Amir Hossain, Ishrat Jahan, Rowshan Hosne Jahan, Jasmin Khan, M A Mannan, Tapas Mazumder, Md. Hafizur Rahman, Md. Ziaul Haque Shaikh, Aysha Siddika, Taslima Akter Sumi, Md. Taqbir Us Samad Talha. Tanzania: Evelyne Assenga, Claudia Hanson, Edward Kija, Rodrick Kisenge, Karim Manji, Fatuma Manzi, Namala Mkopi, Mwifadhi Mrisho, Andrea Pembe. Nepal: Jagat Jeevan Ghimire, Rejina Gurung, Elisha Joshi, Avinash K Sunny, Naresh P. KC, Nisha Rana, Shree Krishna Shrestha, Dela Singh, Parashu Ram Shrestha, Nishant Thakur.

LSHTM: Hannah Blencowe, Sarah G Moxon

EN-BIRTH Expert Advisory Group: Agbessi Amouzou, Tariq Azim, Debra Jackson, Theopista John Kabuteni, Matthews Mathai, Jean-Pierre Monet, Allisyn C. Moran, Pavani K. Ram, Barbara Rawlins, Jennifer Requejo, Johan Ivar Sæbø, Florina Serbanescu, Lara Vaz.

We are also very grateful to fellow researchers who peer-reviewed this paper.

\section{About this supplement}

This article has been published as part of BMC Pregnancy and Childbirth Volume 21 Supplement 1, 2021: Every Newborn BIRTH multi-country validation study: informing measurement of coverage and quality of maternal and newborn care. The full contents of the supplement are available online at https:/bmcpregnancychildbirth.biomedcentral.com/articles/supplements/ volume-21-supplement-1.

\section{Authors' contributions}

The EN-BIRTH study was conceived by JEL, who acquired the funding and led the overall design with support from HR. Each of the three country research teams input to design of data collection tools and review processes, data collection and quality management with technical coordination from HR, GRGL, and DB. The iccdr,b team (notably AER, TT, TH, QSR, SA and SBZ) led the development of the software application, data dashboards and database development with VG and the LSHTM team. IHI (notably DS) coordinated work on barriers and enablers for data collection and use, working closely with LTD. QSR was the main lead for data management working closely with OB, KS and LTD. For this paper, HR and JS led the analyses and first draft of the manuscript working closely with $C H, L T D, A B P$, KP, QSR, NT, KS, TT, RG, MNT, ACM and JEL. All authors revised the manuscript and gave final approval of the version to be published and agree to be accountable for the work. The EN-BIRTH study group authors made contributions to the conception, design, data collection or analysis or interpretation of data. This paper is published with permission from the Directors of Ifakara Health Institute, Muhimbili University of Health and Allied Sciences, icddr,b and Golden Community. The authors' views are their own, and not necessarily from any of the institutions they represent, including WHO.

\section{EN-BIRTH Study Group}

Bangladesh: Qazi Sadeq-ur Rahman, Ahmed Ehsanur Rahman, Tazeen Tahsina, Sojib Bin Zaman, Shafiqul Ameen, Tanvir Hossain, Abu Bakkar Siddique, Aniqa Tasnim Hossain, Tapas Mazumder, Jasmin Khan, Taqbir Us Samad Talha, Rajib Haider, Md. Hafizur Rahman, Anisuddin Ahmed, Shams El Arifeen.

Nepal: Omkar Basnet, Avinash K Sunny, Nishant Thakur, Regina Jurung, Anjani Kumar Jha, Bijay Jha, Ram Chandra Bastola, Rajendra Paudel, Asmita Paudel, Ashish KC.

Tanzania: Nahya Salim, Donat Shamba, Josephine Shabani, Kizito Shirima, Meena Narcis Tarimo, Godfrey Mbaruku (deceased), Honorati Masanja. LSHTM: Louise T Day, Harriet Ruysen, Kimberly Peven, Vladimir Sergeevich Gordeev, Georgia R Gore-Langton, Dorothy Boggs, Stefanie Kong, Angela Baschieri, Simon Cousens, Joy E Lawn.

\section{Funding}

The Children's Investment Fund Foundation (CIFF) are the main funder of the EN-BIRTH Study and funding was administered via The London School of Hygiene \& Tropical Medicine. The Swedish Research Council specifically funded the Nepal site through Lifeline Nepal and Golden Community. We acknowledge the core funders for all the partner institutions. Publication of this manuscript was funded by CIFF. CIFF attended the study design workshop but had no role in data collection, analysis, data interpretation, report writing or decision to submit for publication. The corresponding author had full access to study data and final responsibility for publication submission decision.

\section{Availability of data and materials}

The datasets generated during and/or analysed during the current study are available on LSHTM Data Compass repository, https://datacompass.Ishtm.ac. uk/955/.

\section{Ethics approval and consent to participate}

This study was granted ethical approval by institutional review boards in all operating counties in addition to the London School of Hygiene and Tropical Medicine (Additional file 2).

Voluntary informed written consent was obtained from all observed participants, their families for newborns, and respondents for the qualitative interviews. Participants were assured of anonymity and confidentiality. All women were provided with a description of the study procedures in their preferred language at admission, and offered the right to refuse, or withdraw consent at any time during the study. Facility staff were identified before data collection began and no health worker refused to be observed whilst providing care.

EN-BIRTH is study number 4833, registered at https://www.researchregistry.com.
Consent for publication

Not applicable. 


\section{Competing interests}

The authors declare that they have no competing interests.

\begin{abstract}
Author details
${ }^{1}$ Centre for Maternal, Adolescent, Reproductive \& Child Health (MARCH), London School of Hygiene \& Tropical Medicine (LSHTM), London, UK. ${ }^{2}$ Department of Health Systems, Impact Evaluation and Policy, Ifakara Health Institute (IHI), Dar Es Salaam, Tanzania. ${ }^{3}$ Public Health Sciences - Global Health - Health Systems and Policy, Karolinska Institutet, Stockholm, Sweden. ${ }^{4}$ Department of Obstetrics and Gynaecology, Muhimbili University of Health and Allied Sciences (MUHAS), Dar Es Salaam, Tanzania. ${ }^{5}$ Florence Nightingale Faculty of Nursing, Midwifery \& Palliative Care, King's College London, London, UK. 'Maternal and Child Health Division, International Centre for Diarrhoeal Disease Research, Bangladesh (icddr,b), Dhaka, Bangladesh. ${ }^{7}$ Research division, Golden Community, Lalitpur, Nepal. ${ }^{8}$ Department of Maternal, Newborn, Child and Adolescent Health, World Health Organization, Geneva, Switzerland.
\end{abstract}

\section{Published: 26 March 2021}

\section{References}

1. WHO, UNICEF, UNFPA, World Bank Group, United Nations population division. trends in maternal mortality: 2000 to 2017. Geneva: World Health Organization; 2019..

2. Souza JP, Gülmezoglu AM, Vogel J, Carroli G, Lumbiganon P, Qureshi Z, Costa MJ, Fawole B, Mugerwa Y, Nafiou I. Moving beyond essential interventions for reduction of maternal mortality (the WHO multicountry survey on maternal and newborn health): a cross-sectional study. Lancet. 2013;381(9879):1747-55.

3. Say L, Chou D, Gemmill A, Tunçalp Ö, Moller A-B, Daniels J, Gülmezoglu AM, Temmerman M, Alkema L. Global causes of maternal death: a WHO systematic analysis. Lancet Global Health. 2014;2(6):e323-33..

4. Gallos ID, Papadopoulou A, Man R, Athanasopoulos N, Tobias A, Price MJ, Williams MJ, Diaz V, Pasquale J, Chamillard M. Uterotonic agents for preventing postpartum haemorrhage: a network meta-analysis. Cochrane Database Syst Rev. 2018;12.

5. World Health Organization. WHO recommendations Uterotonics for the prevention of postpartum haemorrhage. Geneva: World Health Organization;..

6. Ricca J, Dwivedi V, Varallo J, Singh G, Pallipamula SP, Amade N, de Luz VM, Bishanga D, Plotkin M, Al-Makaleh B. Uterotonic use immediately following birth: using a novel methodology to estimate population coverage in four countries. BMC Health Serv Res. 2015;15(1):9.

7. MCHIP. National Programs for the prevention and Management of Postpartum Haemorrhage and pre-eclampsia/Eclampsia: a global survey. Washington DC: Maternal and Child Health Intergrated Program; 2012

8. Marchant T, Tilley-Gyado RD, Tessema T, Singh K, Gautham M, Umar N Berhanu D, Cousens S, Schellenberg JRA. Adding content to contacts: measurement of high quality contacts for maternal and newborn health in Ethiopia, north East Nigeria, and Uttar Pradesh, India. PloS one. 2015;10(5): e0126840.

9. Kruk ME, Gage AD, Joseph NT, Danaei G, García-Saisó S, Salomon JA Mortality due to low-quality health systems in the universal health coverage era: a systematic analysis of amenable deaths in 137 countries. Lancet. 2018; 392(10160):2203-12

10. Moller A-B, Newby H, Hanson C, Morgan A, El Arifeen S, Chou D, Diaz T, Say L, Askew I, Moran AC. Measures matter: a scoping review of maternal and newborn indicators. PLoS One. 2018;13(10):e0204763.

11. Jolivet RR, Moran AC, O'Connor M, Chou D, Bhardwaj N, Newby H, Requejo J, Schaaf M, Say L, Langer A. Ending preventable maternal mortality: phase II of a multi-step process to develop a monitoring framework, 2016-2030. BMC Pregnancy Childbirth. 2018;18(1):258.

12. Moran AC, Jolivet RR, Chou D, Dalglish SL, Hill K, Ramsey K, Rawlins B, Say L. A common monitoring framework for ending preventable maternal mortality, 2015-2030: phase I of a multi-step process. BMC Pregnancy Childbirth. 2016;16(1):250..

13. World Health Organisation, UNICEF: Every Newborn; An Action Plan to End Preventable Deaths. 2014.

14. Moxon SG, Ruysen H, Kerber KJ, Amouzou A, Fournier S, Grove J, Moran AC, Vaz LM, Blencowe H, Conroy N, et al. Count Every newborn; a measurement improvement roadmap for coverage data. BMC Pregnancy Childbirth. 2015; 15(2):S8.

15. Day LT, Ruysen H, Gordeev VS, Gore-Langton GR, Boggs D, Cousens S, Moxon SG, Blencowe H, Baschieri A, Rahman AE, et al. Every Newborn-BIRTH protocol: observational study validating indicators for coverage and quality of maternal and newborn health care in Bangladesh, Nepal and Tanzania. J Global Health. 2019;9.

16. World Health Organization, UNICEF: Analysis and Use of Health Facility Data. Guidance for RMNCAH Programme Managers. Working Document. 2019..

17. Croft TN, Marshall AM, Allen CK, et al. Guide to DHS Statistics. Rockville: ICF; 2018.

18. Temmerman M, Lawn JE. Stillbirths count, but it is now time to count them all. Lancet. 2018:392(10158):1602-4.

19. World Health Organization. Global reference list of 100 Core health indicators (plus health-related SDGs), vol. 2018. Geneva: World Health Organization; 2018.

20. Bhattacharya AA, Allen E, Umar N, Usman AU, Felix H, Audu A, Schellenberg JR, Marchant T. Monitoring childbirth care in primary health facilities: a validity study in Gombe State, northeastern Nigeria. J Global Health. 2019;9(2)..

21. Blanc AK, Diaz C, McCarthy KJ, Berdichevsky K. Measuring progress in maternal and newborn health care in Mexico: validating indicators of health system contact and quality of care. BMC Pregnancy Childbirth. 2016;16(1):255..

22. McCarthy KJ, Blanc AK, Warren CE, Kimani J, Mdawida B, Ndwidga C. Can surveys of women accurately track indicators of maternal and newborn care? A validity and reliability study in Kenya. J Global Health. 2016;6(S).

23. Stanton CK, Rawlins B, Drake M, dos Anjos M, Cantor D, Chongo L, Chavane $\mathrm{L}$, da Luz VM, Ricca J. Measuring coverage in MNCH: testing the validity of women's self-report of key maternal and newborn health interventions during the peripartum period in Mozambique. PLoS One. 2013;8(5):e60694..

24. Blanc AK, Warren C, McCarthy KJ, Kimani J, Ndwiga C, RamaRao S. Assessing the validity of indicators of the quality of maternal and nAewborn health care in Kenya. J Global Health. 2016:6(1)..

25. UNICEF. The State of the World's Children 2019: Statistical tables, 2019. New York: UNICEF; 2019

26. Maternal and Child Survival Program: What Data on Maternal and Newborn Health Do National Health Management Information Systems Include? 2018.

27. Bhattacharya AA, Umar N, Audu A, Felix H, Allen E, Schellenberg JR, Marchant T. Quality of routine facility data for monitoring priority maternal and newborn indicators in DHIS2: a case study from Gombe state, Nigeria. PloS One. 2019;14(1):e0211265..

28. Day L, Rahman QS, Rahman A, Salim N, KC A, Ruysen H, Tahsina T, Masanja $H$, Basnet $\mathrm{O}$, Gore-langton $\mathrm{G}$, et al. Assessment of the validity of the measurement of newborn and maternal health-care coverage in hospitals (EN-BIRTH): a mixed-methods observational study. Lancet Global. 2020. https://doi.org/10.1016/S2214-109X(20)30504-0..

29. Day LT, Ruysen H, Gordeev VS, Gore-langton GR, Boggs D, Cousens S, Moxon SG, Blencowe H, Baschieri A, Rahman AE et al: EN-BIRTH Data Collection Tools. 2018.

30. Day LT, Gore-Langton GR, Rahman AE, et al. Labour and delivery ward register data availability, quality, and utility - Every Newborn - birth indicators research tracking in hospitals (EN-BIRTH) study baseline analysis in three countries. BMC Health Serv Res. 2020;20..

31. Performance of Routine Information System Management (PRISM) [https:// www.measureevaluation.org/resources/tools/health-information-systems/ prism] Accessed 26 Oct 20.

32. Shamba D, Day LT, Zaman S b, Sunny AK, Tarimo MN, Peven K, Khan J, Thakur $N$, Talha T u S, Ashish KC, et al. Barriers and enablers to routine register data collection for newborns and mothers: EN-BIRTH multi-country study Pregnancy Childbirth. 2020. https://doi.org/10.1186/s12884-020-03517-3.

33. World Health Organization. Data quality review: modules 1-3: framework and metrics, desk review of data quality, data verification and system assessment. Geneva: World Health Organization; 2017.

34. Shakibazadeh E, Namadian M, Bohren M, Vogel J, Rashidian A, Nogueira Pileggi V, Madeira S, Leathersich S, Tunçalp Ö, Oladapo O. Respectful care during childbirth in health facilities globally: a qualitative evidence synthesis Bjog. 2018;125(8):932-42..

35. World Health Organization. The prevention and elimination of disrespect and abuse during facility-based childbirth: WHO statement. Geneva: World Health Organization;

36. White Ribbon Alliance: What Women Want. https://www. whiteribbonalliance.org/whatwomenwant/. Accessed 2 Dec 2020. 
37. Boerma T, Ronsmans C, Melesse DY, Barros AJ, Barros FC, Juan L, Moller A-B, Say L, Hosseinpoor AR, Yi M. Global epidemiology of use of and disparities in caesarean sections. Lancet. 2018;392(10155):1341-8.

38. Broughton El, Ikram AN, Sahak I. How accurate are medical record data in Afghanistan's maternal health facilities? An observational validity study. BMJ Open. 2013:3(4):e002554..

39. Gimbel S, Mwanza M, Nisingizwe MP, Michel C, Hirschhorn L. Improving data quality across 3 sub-Saharan African countries using the consolidated framework for implementation research (CFIR): results from the African health initiative. BMC Health Serv Res. 2017;17(3):828.

40. O'Hagan R, Marx MA, Finnegan KE, Naphini P, Ng'ambi K, Laija K, Wilson E, Park L, Wachepa S, Smith J. National assessment of data quality and associated systems-level factors in Malawi. Global Health Sci Pract. 2017;5(3): 367-81..

41. Ouedraogo M, Kurji J, Abebe L, Labonté R, Morankar S, Bedru KH, Bulcha G, Abera M, Potter BK, Roy-Gagnon M-H. A quality assessment of health management information system (HMIS) data for maternal and child health in Jimma zone, Ethiopia. PloS One. 2019;14(3):e0213600..

42. Frøen JF, Myhre SL, Frost MJ, Chou D, Mehl G, Say L, Cheng S, Fjeldheim I, Friberg IK, French S. eRegistries: electronic registries for maternal and child health. BMC Pregnancy Childbirth. 2016;16(1):11..

43. Maina I, Wanjala P, Soti D, Kipruto H, Droti B, Boerma T. Using health-facility data to assess subnational coverage of maternal and child health indicators, Kenya. Bull World Health Organ. 2017;95(10):683.

44. Keating R, Merai R, Mubiri P, Kajjo D, Otare C, Mugme D, Weissglas F, Waiswa P, Otieno P, Kirumbi L, et al. Assessing Effects of Data Quality Stregthening Campaign on Completeness of Key Fields in Facility-based Maternity Registers in Kenya and Uganda. East Afr J Appl Health Monitoring Evaluation. 2019;3.

45. Mutale W, Chintu N, Amoroso C, Awoonor-Williams K, Phillips J, Baynes C, Michel C, Taylor A, Sherr K. Improving health information systems for decision making across five sub-Saharan African countries: implementation strategies from the African health initiative. BMC Health Serv Res. 2013;13(2):S9.

46. Wagenaar BH, Hirschhorn LR, Henley C, Gremu A, Sindano N, Chilengi R. Data-driven quality improvement in low-and middle-income country health systems: lessons from seven years of implementation experience across Mozambique, Rwanda, and Zambia. BMC Health Serv Res. 2017;17(3):830..

47. Montagu D, Sudhinaraset M, Diamond-Smith N, Campbell O, Gabrysch S, Freedman L, Kruk ME, Donnay F. Where women go to deliver: understanding the changing landscape of childbirth in Africa and Asia. Health Policy Plan. 2017;32(8):1146-52..

48. Soltani H, Hutchon DR, Poulose TA. Timing of prophylactic uterotonics for the third stage of labour after vaginal birth. Cochrane Database Syst Rev. 2010;8.

49. Ker K, Roberts I, Chaudhri R, Fawole B, Beaumont D, Balogun E, Prowse D, Pepple T, Javaid K, Kayani A. Tranexamic acid for the prevention of postpartum bleeding in women with anaemia: study protocol for an international, randomised, double-blind, placebo-controlled trial. Trials. 2018; 19(1):712.

50. Improving the Availability of Quality Oxytocin [https://www.ghsupplychain.org/ key-initiatives/improving-availability-quality-oxytocin] Accessed 26 Oct 20.

51. Anyakora C, Oni Y, Ezedinachi U, Adekoya A, Ali I, Nwachukwu C, Esimone C, Abiola V, Nwokike J. Quality medicines in maternal health: results of oxytocin, misoprostol, magnesium sulfate and calcium gluconate quality audits. BMC Pregnancy Childbirth. 2018;18(1):44..

52. Torloni M, Gomes Freitas C, Kartoglu U, Metin Gülmezoglu A, Widmer M. Quality of oxytocin available in low-and middle-income countries: a systematic review of the literature. Bjog. 2016;123(13):2076-86..

53. Victora CG. What's the denominator? Lancet. 1993;342(8863):97-9

54. World Health Organization. MoHFW launches new real time Health Management Information System online portal in five states. 2019..

55. Government of Tamil Nadu. In: Dept of Administrative Reforms and Public Grievances Gol, editor. Health Management Information System. India: Government of Tamil Nadu;..

56. Munos MK, Blanc AK, Carter ED, Eisele TP, Gesuale S, Katz J, Marchant T, Stanton CK, Campbell H. Validation studies for population-based intervention coverage indicators: design, analysis, and interpretation. J Global Health. 2018;8(2).

57. Carter ED, Ndhlovu M, Eisele TP, Nkhama E, Katz J, Munos M. Evaluation of methods for linking household and health care provider data to estimate effective coverage of management of child illness: results of a pilot study in Southern Province, Zambia. J Global Health. 2018;8(1)

58. Do M, Micah A, Brondi L, Campbell H, Marchant T, Eisele T, Munos M. Linking household and facility data for better coverage measures in reproductive, maternal, newborn, and child health care: systematic review. J Global Health. 2016;6(2)..

59. Kanyangarara M, Chou VB, Creanga AA, Walker N. Linking household and health facility surveys to assess obstetric service availability, readiness and coverage: evidence from 17 low-and middle-income countries. J Global Health. 2018:8(1)..

60. Willey B, Waiswa P, Kajjo D, Munos M, Akuze J, Allen E, Marchant T. Linking data sources for measurement of effective coverage in maternal and newborn health: what do we learn from individual-vs ecological-linking methods? J Global Health. 2018;8(1)..

\section{Publisher's Note}

Springer Nature remains neutral with regard to jurisdictional claims in published maps and institutional affiliations.
Ready to submit your research? Choose BMC and benefit from:

- fast, convenient online submission

- thorough peer review by experienced researchers in your field

- rapid publication on acceptance

- support for research data, including large and complex data types

- gold Open Access which fosters wider collaboration and increased citations

- maximum visibility for your research: over $100 \mathrm{M}$ website views per year

At $\mathrm{BMC}$, research is always in progress.

Learn more biomedcentral.com/submissions 